Manuscript of article published in Public Money and Management (April 2019).

Link to published version here:

https://doi.org/10.1080/09540962.2019.1592908

\title{
The New Civic Leadership: place and the co-creation of public innovation
}

\author{
Robin Hambleton, University of the West of England, Bristol, UK and \\ Director of Urban Answers
}

\begin{abstract}
This paper discusses the role of place-based leadership in stimulating the cocreation of inclusive public services and outcomes. A conceptual framework, designed to illuminate the forces shaping the power of place, and to provide a fresh way of envisaging the nature of modern local leadership and public management, is presented. This New Civic Leadership (NCL) framework, one that can be contrasted with the outdated idea of New Public Management (NPM), is being used by Marvin Rees, Mayor of Bristol, to guide the development of the City Office approach to urban governance in Bristol, UK. This effort to unite public purpose in a city is discussed, and emerging themes relating to the role of place-based leadership in spurring new ways of cocreating public service futures are explored.
\end{abstract}

Keywords: civic leadership; local governance; co-creation; innovation in public management; place

\section{Author}

Robin Hambleton is Emeritus Professor of City Leadership, Centre for Sustainable Planning and Environments, University of the West of England, Bristol, UK and Director of Urban Answers - see www.urbananswers.co.uk

Email: robin.hambleton@uwe.ac.uk

\section{Introduction}

In response to a range of complex challenges a growing number of cities across the world are developing new forms of collaborative governance. The literature on collaboration in public policy and public management is expanding (Margerum, 2011; Agranoff, 2012; Williams, 2012; Emerson and Nabatchi, 2015; Torfing et al 2016; Ansell, et al 2017), as is the literature on user engagement and community involvement (Oliver and Pitt, 2013; Norton and Hughes, 2017). There appears to be a growing recognition that the state 
needs to become much more inventive in working with other stakeholders to achieve societal goals. A consequence is that, as noted by Bovaird et al (2017), a new vocabulary relating to public service reform is emerging, one that makes widespread use of the prefix 'co'.

In the 1980s New Public Management (NPM), which involves the use of private sector management practices in the public sector, gained popularity in many countries (Hood 1991). In essence, the approach stems from the belief that government should be run like a private business. Various writers have shown that privatization, marketisation, treating citizens as if they were selfinterested consumers, and similar strategies have serious limitations (Hoggett, 1991; Barzelay, 2001). Mintzberg (1996) offered a particularly robust critique of NPM arguing that to treat citizens as customers of public service is to completely misunderstand the nature of the relationship between people and their government. In academic circles, partly as a reaction to the limitations of NPM, interest in new forms of public governance, ones involving co-production of public services, has grown considerably (Osborne 2010; Pestoff et al 2012; Bovaird and Loeffler, 2015).

The New Civic Leadership (NCL), presented in this article, offers a clear alternative to NPM. It involves strong, place-based leadership acting to cocreate new solutions to public problems by drawing on the complementary strengths of civil society, the market and the state. The NCL approach, which is set out in detail elsewhere (Hambleton 2015, 66-74), is aligned with recent thinking relating to co-production. For example, it takes account of the shift from government to governance and provides a way of imagining different relationships between citizens, the state and other stakeholders. However, it is distinctive in that it: draws attention to the importance of the power of place in public policy making; stresses the importance of improvisation and radical innovation in local governance; and highlights the role of place-based leadership in spurring the co-creation of new ways of enhancing the quality of life in a locality.

Brandsen and Pestoff (2006) provide a helpful way of mapping the relatively new terrain of public governance by distinguishing between co-production, comanagement and co-governance. Interestingly, they suggest that cogovernance involves developing more strategic relationships between the state and other actors than the other two because it involves stakeholders working together on policy formulation. In their model co-management refers to interactions between organizations, whilst co-production refers to voluntary efforts by individual citizens. In this article our focus will be on the leadership of new forms of co-governance at the local level.

\section{Framing the power of place}

Place-based leaders are not free agents able to do exactly as they choose. On the contrary, various powerful forces shape the context within which civic leaders operate. These forces do not, however, disable local leadership and cannot prevent local leaders from co-creating new possibilities. Rather they place limits on what urban leaders may be able to accomplish in particular 
places and at particular moments in time. Figure 1 provides a simplified picture of the four sets of forces that shape the world of place-based governance in any given locality.

Figure 1 Framing the political space for place-based governance

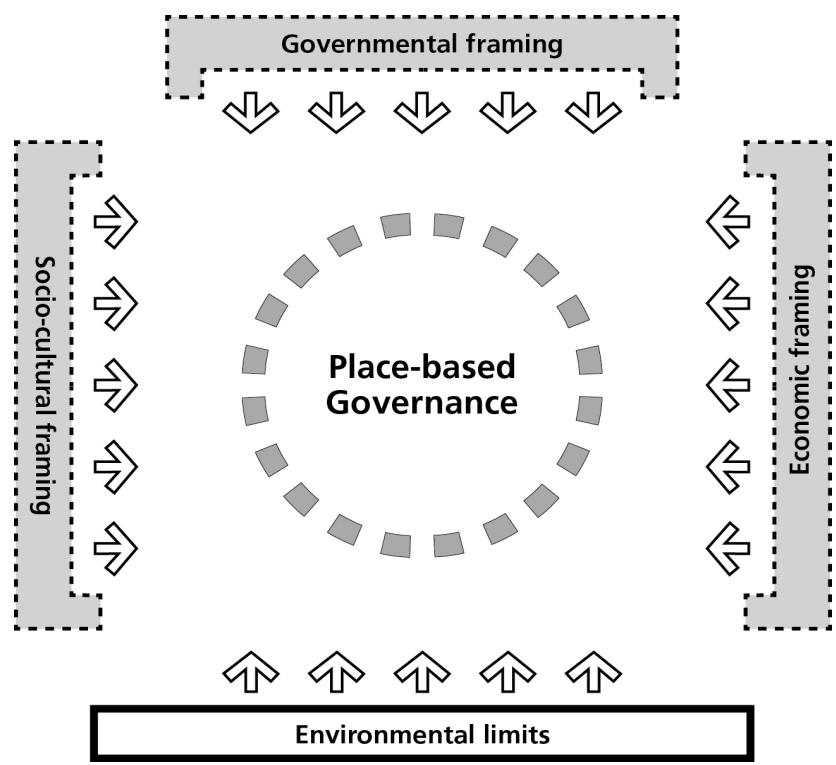

Source: Hambleton (2015) p 114

At the bottom of the diagram, are the non-negotiable environmental limits. Ignoring the fact that cities are part of the natural ecosystem is irresponsible, and failure to pay attention to environmental limits will store up unmanageable problems for future generations (Boone and Modarres, 2006; Bulkeley, 2013). This side of the square is drawn with a solid line because, unlike the other sides of the square, these environmental limits are, despite the claims of climate change deniers like US President Donald Trump, non-negotiable.

On the left hand side of the diagram are socio-cultural forces - these comprise a mix of people (as actors) and cultural values (that people may hold). Here we find the rich variety of voices found in any city - including the claims of activists, businesses, artists, entrepreneurs, trade unionists, religious organizations, community-based groups, citizens who vote, citizens who don't vote, children, newly arrived immigrants, anarchists and so on. Places have traditions and identities that are built up over a long period of time (Bell and de-Shalit, 2011). The people of the city will have different views about the kind of city they wish to live in, and they will have differential capacity to make these views known (Davies and Imbroscio, 2010). Some, maybe many, will claim a right to the city (Brenner et al, 2012). We can assume that, in democratic societies at least, elected leaders who pay little or no attention to these political pressures should not expect to stay in office for too long. Expression of citizen voice, to use Hirschman's term (1970), will see them dismissed at the ballot box. 
On the right hand side of the diagram are the horizontal economic forces that arise from the need for localities to compete, to some degree at least, in the wider marketplace - for inward investment and to attract talented people. Various studies have shown that, contrary to neo-liberal dogma, it is possible for civic leaders to bargain with business (Savitch and Kantor, 2002).

On the top of Figure 1 we find the legal and policy framework imposed by higher levels of government. In some countries this governmental framing will include legal obligations decreed by supra-national organizations. For example, local authorities in countries that are members of the European Union (EU) are required to comply with EU laws and regulations, and to take note of EU policy guidance. Individual nation states determine the legal status, fiscal power and functions of local authorities within their boundaries. These relationships are subject to negotiation and renegotiation over time.

It is clear that Figure 1 simplifies a much more complex reality. The space available for local agency is always shifting, and a key task of local leaders is to be alert to the opportunities for advancing the power of their place within the context of the framing forces prevailing on their area at the time.

Figure 1 indicates that place-based governance, shown at the centre, is porous. Successful civic leaders are constantly learning from the environment in which they find themselves in order to discover new insights, co-create new solutions and advance their political objectives. Note that the four forces are not joined up at the corners to create a rigid prison within which civic leadership has to be exercised. On the contrary the boundaries of the overall arena are, themselves, malleable. Depending on the culture and context, imaginative civic leaders may be able to disrupt the pre-existing governmental frame and bring about an expansion in place-based power.

\section{The New Civic Leadership}

NCL involves strong, place-based leadership acting to co-create new solutions to public problems by drawing on the complementary strengths of civil society, the market and the state. If we are to understand how effective, place-based leadership works, we need a conceptual framework that highlights the role of local leaders in facilitating public service innovation. Here I provide a sketch of a possible framework.

Figure 2 suggests that in any given locality place-based governance is likely to comprise five overlapping realms of place-based leadership, with leaders in each realm drawing on different sources of legitimacy:

- Political leadership - referring to the work of those people elected to leadership positions by the citizenry

- Public managerial/professional leadership - referring to the work of public servants appointed by local authorities, governments and third 
sector organizations to plan and manage public services, and promote community wellbeing

- Community leadership - referring to the many civic-minded people who give their time and energy to local leadership activities in a wide variety of ways

- Business leadership - referring to the contribution made by local business leaders and social entrepreneurs, who have a clear stake in the long-term prosperity of the locality

- Trade union leadership - referring to the efforts of trade union leaders striving to improve the pay and working conditions of employees

Figure 2: The realms of place-based leadership

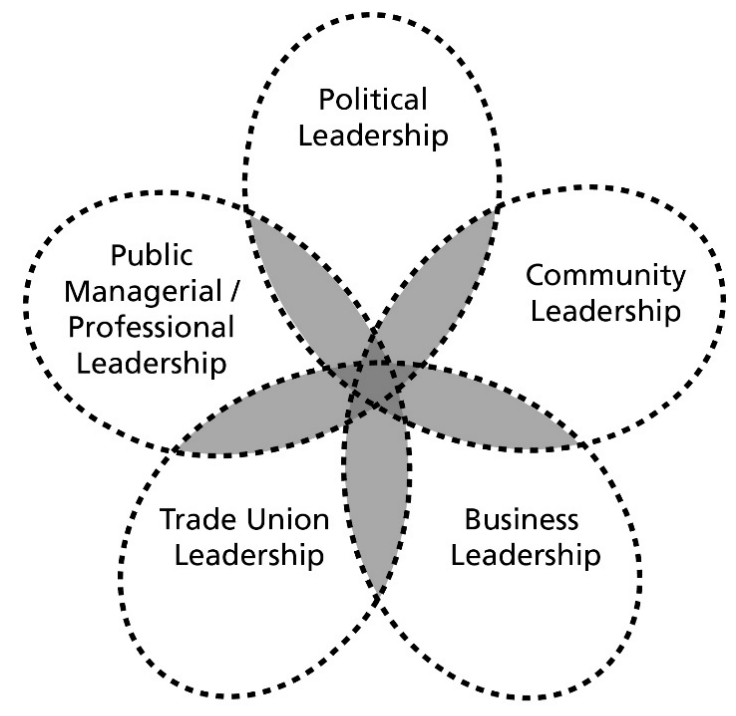

Potential innovation zones

Source: Hambleton (2015) p 127

These leadership roles are all important in cultivating and encouraging public service innovation and, crucially, they overlap. The areas of overlap can be describes as innovation zones - areas providing many opportunities for inventive behavior. This is because different perspectives are brought together in these zones and this can enable active questioning of established approaches.

It is fair to say that the areas of overlap in Figure $\mathbf{2}$ are often experienced as conflict zones, rather than innovation zones. These spaces do, of course, provide settings for power struggles between competing interests and values. Moreover, power is unequally distributed within these settings. This is 
precisely why place-based leadership matters. The evidence from my research on urban governance is that civic leadership is critical in ensuring that the innovation zones are orchestrated in a way that promotes a culture of listening that can, in turn, lead to innovation. Civic leaders are, of course, not just 'those at the top'. All kinds of people can exercise civic leadership and they may be inside or outside the state. The author's definition of leadership is: 'Shaping emotions and behavior to achieve common goals' (Hambleton 2007 , p. 174). This definition puts emotions centre stage and stresses the importance of the co-creation of new possibilities.

Having explained the five realms of place-based leadership it is now possible to advance the presentation by locating the five realms within the broader context outlined earlier - see Figure 3.

Figure 3: Place-based leadership in context

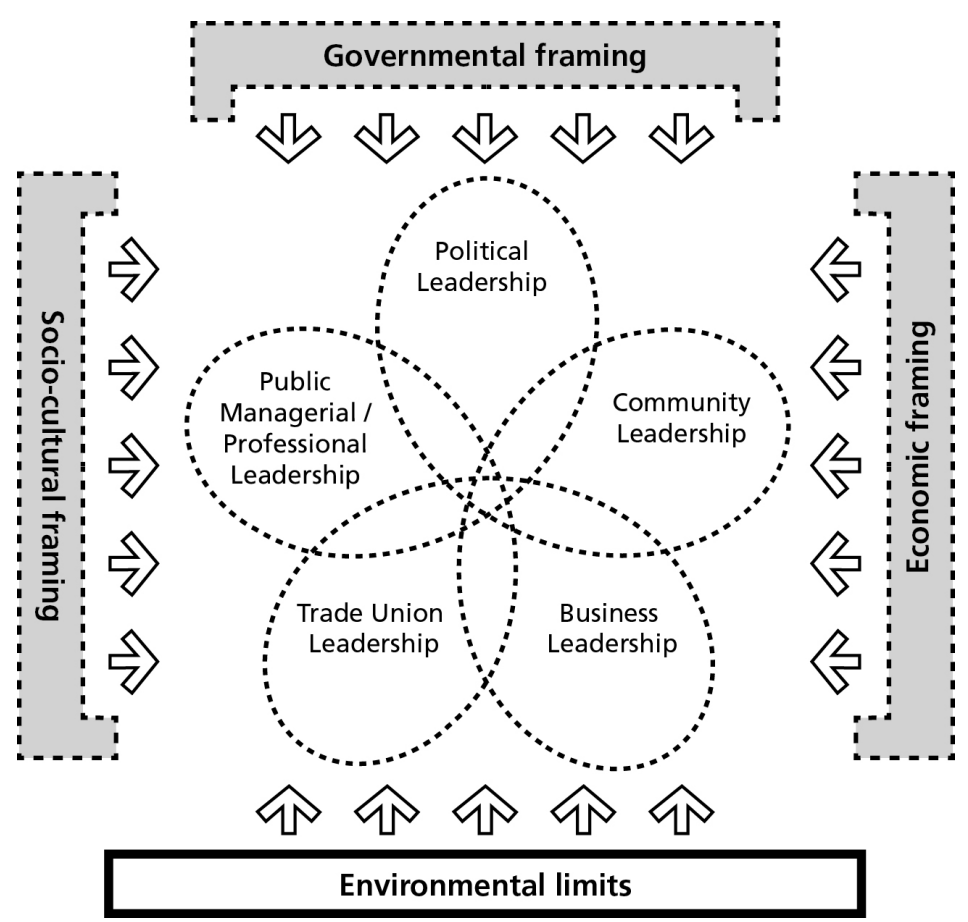

Source: Hambleton (2015) p 128

\section{The introduction of mayoral governance in Bristol, UK}

In 2011 the UK Coalition Government passed the Localism Act which required, inter alia, the big cities of England to hold referenda to enable local citizens to decide whether or not they would like to adopt a directly elected mayor form urban governance. In the event ten referenda were held in May 2012. Nine cities voted 'no'. Bristol, by contrast, voted 'yes' and a mayoral election was organized for November 2012. A longitudinal study of the impact of mayoral governance on the city of Bristol has been carried out, and this 
shows that the change in leadership arrangements has had a major impact on the governance, particularly the leadership, of the city (Hambleton and Sweeting, 2014; Hambleton and Sweeting 2015; Sweeting and Hambleton, 2017).

Given that the research evidence is set out elsewhere a short summary of key findings will be sufficient for the purposes of this paper. On the positive side the research shows that many civic leaders and citizens felt that the leadership of the city improved following the introduction of a directly elected mayor. Leadership was felt to be far more visible, a clear vision for the city was set out, and few would deny that Mayor George Ferguson, an independent politician who became the first directly elected mayor of Bristol, was very successful in using the position of the office of mayor to raise the profile of the city nationally and internationally.

On the down side the research revealed that this particular version of the mayoral model can concentrate too much power in the hands of one individual, and that citizen trust in decision-making and timeliness of decisionmaking did not improve that much. Mayor Ferguson certainly adopted a top down style of leadership and he also centralised power in the mayor's office. Many councillors felt excluded from decision-making, and formed a negative view of the mayor. Interestingly, members of the public in different parts of Bristol tended to think differently about the impacts of the reform. Often, but not universally, those people living in the better off parts of Bristol are inclined to view the reform more positively than those living in the less well off parts of Bristol.

In May 2016 the citizens of Bristol elected a new mayor. Marvin Rees, a young and charismatic candidate, delivered an emphatic victory for the Labour Party. Mayor Rees, who is mixed race and was brought up in the less well off parts of Bristol, has a very different leadership style from Mayor Ferguson. He sees himself as a facilitative leader and places a high value on building good relationships between state and non-state actors in the city. Bristol has a buoyant economy and is prosperous, but social and economic divisions are significant and they are growing. Mayor Rees is striving to strengthen place-based collaborative governance in order to tackle inequality in the city and create, in the words of his first Annual Mayoral Public Lecture given in October 2016, a 'City for all'.

Before turning to consider the recent innovations in collaborative governance taking place in Bristol it is important to refer to the national policies for local government pursued by both the UK Coalition Government (2010-15) and the Conservative Government (since 2015). This is because these policies have placed major constraints on the exercise of place-based leadership by Mayor Ferguson and Mayor Rees, as well as local authority leaders across the entire country (Latham, 2017). In essence the UK central state has chosen to decimate central government financial support to local government, an approach described as 'super-austerity' by some scholars (Lowndes and Gardner 2016). In the Bristol case the cut in central government financial 
support is from $£ 201$ million a year in $2010 / 2011$ to $£ 45$ million a year in 2019/2020 - that's a 78\% cut (Hambleton 2017).

This central government attack on local democracy draws attention to the importance of understanding the way forces outside a place can impact the public leadership and public management of a place - see Figure 1. In the UK case the governmental framing, shown at the top of the diagram, has become over bearing. This contrasts with the experience of many countries where locally elected governments enjoy constitutional protection and have significant fiscal power.

\section{The City Office Concept - a new way of governing a city?}

Marvin Rees began to develop the idea of creating a City Office in the summer of 2015 . He was, at that time, preparing to compete to be selected as the Labour Party candidate to run for Mayor of Bristol in the May 2016 local election. He was keen to offer some fresh ideas on how to go about the task of city governance. In the simplest of terms the City Office represents an attempt to unite public purpose in the city, one that seeks to bind together all those who care about the city in a much more effective collaborative effort. The approach is strongly place-based in the sense that it draws energy and momentum from the positive feelings people have about the place where they live.

In a headline on his campaign website in August 2015 Rees signalled the nature of the shift he had in mind: 'Bristol shouldn't be run from the council chamber'. This, in itself, was a radical statement for a politician seeking public office. In various speeches he explained that, while elected local government is enormously important in city governance, it is the way that public organisations work in creative collaboration with other interests in the city that holds out real promise for making social and economic progress. Intellectual underpinning for the City Office concept is supported by, inter alia, research on successful place-based leadership in fourteen different countries (Hambleton 2015). Mayor Rees is using the evidence set out in the author's book to guide his approach to place-based leadership. In particular, he finds the 'flower diagram', shown in Figure 2, to be helpful and is keen to build connections between the different realms of leadership in the city. The City Office is located at the heart of this flower diagram.

The City Office aims to mobilise energies from the different realms of leadership for the benefit of the whole city. The central ethos is to focus on making an additional contribution over and above the activities of existing agencies and established collaborative arrangements. The City Office does not duplicate or replace existing networks and structures. Rather it tries to add value by accessing networks and resources that otherwise would not be available.

From the outset the City Office approach has emphasised the co-creation of new possibilities for progressive action. This is unusual. The longestablished, and increasingly outdated, approach to civic leadership, 
sometimes referred to as the 'city boss' model in American urban political science, anticipates the newly elected mayor or leader of a city setting out a vision and then, more or less, instructing or pressuring city hall officials to implement the vision (Yates 1977; John and Cole, 1999). Mayor Rees rejects simplistic top-down management models of this kind. He stresses that effective place-based leadership requires a much more inclusive and much more flexible approach, one that involves a process of opening up conversations with different stakeholders and one that involves risk taking and experiment.

\section{The style of mayoral leadership}

A few days after being elected Mayor Rees, at his Swearing-In Ceremony on 9 May 2016 in the M-Shed, a museum documenting the history of the people of Bristol, demonstrated his strong commitment to developing a collective, not an individualised, approach to city leadership. Note that this ceremony was not held in City Hall. Rather this important civic event was located in a public building in the centre of the city that is visited by large numbers of Bristol residents. The symbolism was clear - City Hall is only part of the governance of the city.

Most unusually for a Swearing-In Ceremony the Mayor was not the only speaker on the platform offering ideas on the future of the city. After the formal Swearing-In procedure Mayor Rees introduced Miles Chambers, later to become the first Bristol Poet Laureate, who read a passionate poem about the history of the city. Rees then invited three other civic leaders in Bristol to offer their contributions: a senior health services manager; the ViceChancellor of one of the two local universities; and the Bristol Area Commander of Avon and Somerset Police. Rees did not know in advance what these civic leaders were going to say. From the get-go, then, Rees was signalling his interest in sharing power and valuing the leadership contributions of other agencies and actors. In his own speech Rees emphasised that the City Office model of city leadership was intended to improve partnership working and would emphasise the co-creation of new ideas and ways of working.

\section{The City Office approach to co-creating public services}

It is possible to summarise the main features of Rees's City Office way of working by referring briefly to five elements in the approach. First, inclusive City Gatherings of civic leaders, drawn from the realms of place-based leadership shown in Figure 2, have been held on a regular basis since the City Office Founders Meeting held in July 2016. City Gatherings, which take place every few months in different locations across the city, create highly interactive 'city conversations', with participants working together in crosssectoral teams, to examine the major challenges facing the city and to explore ideas on how to tackle them. Typically City Gatherings attract between 70 and 180 participants. 
Second, Rees has created an innovation zone in City Hall just outside the Mayor's Office. People, from any of the realms of leadership in the city, who are working on activities relating to the City Office agenda, are invited to work in this space on Tuesdays and Wednesdays. In addition, the City Office organises regular presentations and workshops on Tuesday mornings. The creation of this space, clearly an innovation zone within the New Civic Leadership approach to co-governance, is a simple step that has already enabled a good deal of informal communication to take place between stakeholders from the different realms of place-based leadership shown in Figure 2.

A third element in the model is to create and deliver specific City Office collaborative projects on pressing issues. A good example is provided by the Street Homelessness Challenge project. In late 2016 Rees asked local leaders to work together to create 100 extra beds for homeless people in the first 100 days of 2017. A project group, chaired by the City Office Director, was set up to develop ways of achieving this ambitious target. City Office partners launched a 'spectrum of activity' to tackle homelessness (Morris 2017). This approach brought in actors not normally involved in addressing this challenge, for example, local businesses.

Fourth, the One City Plan, now in preparation, is designed to deliver the main strategic aim of the Bristol City Office. It is orchestrating the creation of a 'big picture' strategy for the future development of the city, one that looks forward to 2050 , and one that agencies are expected to commit to.

The fifth element in the City Office approach is the development of placebased leadership talent. The City Gatherings, mentioned earlier, identified the importance of developing and delivering new kinds of civic leadership programmes, ones that target under-represented groups in the city. The idea is for the City Office to orchestrate a step-change in the provision of placebased leadership programmes - ranging from city leadership courses for young people (under 18s) through to advanced place-based leadership workshops for senior leaders from the realms of leadership shown in Figure 2.

The Bristol City Office approach to co-creating public service is not without its critics. For example, some of those who are opposed to the central government attack on both local public services and local democracy fear that creative approaches to local collaboration can become a distraction. They argue that a City Office in a particular city is unlikely to make much difference in a country that is so centralized. They have a point. Indeed, cross-national comparative research shows that, in countries where public power is much more dispersed than in the UK, local public leaders have been able to pursue world-leading approaches to public innovation (Hambleton, 2015). However, it would be misguided to conclude that place-based collaborative action is pointless. The efforts of local leaders across the UK, not just those in Bristol, are making a difference to the local quality of life, notwithstanding the constraints imposed by Whitehall. 
Another criticism is that a consensual approach, one that strives to bring together different stakeholders just takes too long, when a more decisive approach to place-based leadership is needed. It is true that relationship building takes time and, given the City Office approach has only been in operation since the summer of 2016 , it is too early to judge whether or not it is going to be effective in shaping the emotions and behaviour of civic leaders in a progressive direction. Debates about the strengths and weaknesses of the City Office model revolve, to some extent, around different conceptions of leadership. Those who remain attracted to the idea of top down leadership exercised by a skilled executive or expert telling people what to do are unlikely to be impressed with the model. However, those who take the view that successful modern leadership is, at root, a collaborative affair will see virtue in the model. Research on 'living leadership' is relevant to this debate:

'Leadership is not then about knowing the answer and inspiring others to follow. It is the capacity to release the collective intelligence and insights of groups and organizations. It is helping people to find their own answers' (Binney et al, 2012, pp. 10-11).

\section{Emerging themes for public leadership and management}

A number of important themes emerge from the analysis presented above and four are highlighted here.

\section{Rallying the power of place}

The evidence presented in this paper, and in related research on other innovative cities, suggests that place-based leadership can play a vital role in energising and promoting the power of place. The concepts presented here suggest that the power of place is constrained by various forces - see Figure 1. Wise central and state governments realise that elected local authorities are a major asset and they encourage the development of independent, innovative municipalities. However, even in countries where the central state does not value local government, as in the UK at the present time, there is always some political space available to local actors. Effective place-based leaders, depending on the geo-political context, are capable of expanding the power of place, and there are many examples that illustrate this point. Place, and the feelings of attachment people have to their place, are an important resource for those seeking to strengthen the co-production and co-creation of new solutions to public policy challenges.

The City Office approach to co-governance in Bristol clearly aims to enhance the power of place. Note that this is not just the political and fiscal power of Bristol City Council, but also the collective power of people living in the city. The City Office is still at a very early stage of development and it is unwise to claim too much. However, the model is already attracting interest from other cities and localities in the UK. Moreover, a major report from the RSA Inclusive Growth Commission refers positively to the Bristol City Office approach, praising it as a promising example of 'whole place leadership' (Royal Society of Arts 2017, p. 35). In a world in which distant, unaccountable 
decision-makers have gained too much power this idea of appealing to the feelings people have about the place where they live and work is capable of attracting a good deal of support.

\section{Understanding the role of leadership in public service improvisation}

The role of leadership in bringing about the co-creation of public services has been neglected in the literature, albeit with one or two notable exceptions (Bason, 2010). The argument presented in this article is that place-based leadership can have a major impact on the trajectory of public service innovation and it follows that the role of leadership should be given more explicit attention in future studies of co-production. Research on Bristol, as well as studies of other innovative cities, suggests that effective local leaders are able to connect to place-based feelings of loyalty and civic identity and inspire a process of imaginative risk taking. Elsewhere I have described this approach to public leadership as the orchestration of social discovery (Hambleton, 2015, pp. 161-170).

Figure 3 can, perhaps, provide a useful starting point for understanding local power structures and the role of civic leadership in creating innovation zones which can generate new ways of thinking and new solutions. The meaning of 'leadership' has long been contested but, as Bolden et al (2016) explain, there is now renewed pressure to rethink the meaning of leadership in an uncertain world. The long-established view that sees leadership as a top-down affair in which senior people issue instructions to subordinates is well past its 'sell-by' date. A contrasting view, facilitative leadership, emphasises the importance of leaders listening to diverse views and building coalitions. In this model leadership is not about knowing the answers and encouraging others to follow. Rather, it is the capacity to spot talent and release collective problemsolving capacity. As explained by Barrett (2012), who draws on his experience as a jazz musician, civic leaders need to become skilled at improvisation - the art of adjusting, flexibly adapting, learning through trialand-error initiatives and inventing ad hoc responses. Effective civic leaders, and the leaders involved in the Bristol City Office approach provide some outstanding examples, strive to create a culture in which risk taking and experimentation are valued and encouraged.

\section{The creation of innovation zones}

A central claim in this paper, and it lies at the heart of the Bristol City Office concept, is that successful civic leadership brings people with different backgrounds and experiences together into a single purposive process. This is easier said than done, but it can be done. Wise civic leadership requires the creation of innovation zones - sometimes referred to as 'space for dialogue' (Oliver and Pitt 2013, pp. 198-199) - and the promotion of a culture of listening within these zones that can, in turn, lead to innovation. There are many ways of creating these new spaces or zones, and the Bristol City Office approach is using a variety of methods to engage stakeholders, including young people, from different backgrounds in new ways. 
Three examples of innovation zones invented by the Bristol City Office can be mentioned. First, the City Gatherings held so far represent a new way of bringing civic leaders from the five realms of leadership in the city together. These gatherings have taken place at different locations and, while the format of these events has been diverse, they are always designed to be highly interactive. Outside facilitators from the private sector and the local universities have provided assistance at no charge to the City Office. Second, the open plan office area in City Hall, close to the Mayor's Office, is another imaginative step. This experimental, unpredictable way of working is helping to build trust between different actors. Third, the various project groups bring new kinds of people into a given conversation. Thus, the project group on tackling homelessness includes representatives from realms of civic leadership who might not normally identify with this topic - for example, representatives from the business community.

\section{International city-to-city learning and exchange}

International learning relating to city governance, urban innovation and cocreation is nothing new. For example, Aristotle despatched his helpers to collect the constitutions of over one hundred city-states, which he then compared to derive general political principles. However, the process of international city-to-city exchange has received a rocket boost in recent times. In the last thirty years or so, globalisation has led to a spectacular increase in the intensity and velocity of international exchange in all spheres of life.

Campbell (2012) believes that forward-looking city leaders are keen to acquire new knowledge from cities in other countries, and the international transmission of ideas, and the values behind them, is now an inextricable part of urban innovation.

These ideas relating to international city-to-city learning are relevant to the Bristol City Office approach to urban governance. The City Council has prepared a ten-year strategy designed to align the international priorities of the council and city partners (Bristol City Council, 2017). Mayor Rees is very international in his outlook and is strongly committed to working with other cities, in the UK and further afield, to develop progressive alliances. He is active in the relatively new Global Parliament of Mayors, a rapidly expanding organisation that is strongly committed to advancing the power of place in our globalising world. Bristol will host the Annual Summit of the Global Parliament of Mayors in October 2018.

In conclusion, this paper suggests that future efforts at public service reform should pay much more attention to the power of place and, just as important, the role of local public leadership in inspiring the co-creation of new possibilities for inclusive public outcomes.

\section{References}

Agranoff, R. (2012) Collaborating to Manage. A primer for the public sector. Washington, DC: Georgetown University Press. 
Ansell C., Sorensen E. and Torfing J. (2017) 'Improving policy implementation through collaborative policymaking', Policy and Politics, 45, 3, pp. 467-86.

Barrett F. J. (2012) Yes to the Mess. Surprising leadership lessons from jazz. Boston MA: Harvard Business Review Press.

Barzelay M. (2001) The New Public Management. Improving research and policy dialogue. Berkeley, CA: University of California Press.

Bason C. (2010) Leading Public Sector Innovation. Co-creating for a better society. Bristol: The Policy Press.

Bell D. A. and de-Shalit A. (2011) The Spirit of Cities. Why the identity of a city matters in a global age. Princeton: University of Princeton Press.

Binney G., Williams C. and Wilke G. (2012) Living leadership. A practical guide for ordinary heroes. Harlow: Pearson Education Limited.

Bolden R., Witzel W. and Linacre N. (eds) (2016) Leadership paradoxes. Rethinking leadership for an uncertain world. London: Routledge.

Boone C. G. and Modarres A. (2006) City and Environment. Philadelphia PA: Temple University Press.

Bovaird T., Flemig S., Loeffler E. and Osborne S. P. (2017) ‘Debate: Coproduction of public services and outcomes', Public Money and Management, 37, 5 pp. 363-364.

Bovaird T. and Loeffler E. (eds) (2015) Public Management and Governance. London: Routledge.

Brandsen T. and Pestoff V. (2006) 'Co-production, the third sector and the delivery of public service', Public Management Review, 8, 4, pp.493-501.

Brenner N., Marcuse P. and Mayer M. (eds) (2012) Cities for people, not for profit. Critical urban theory and the right to the city. Abingdon: Routledge.

Bristol City Council (2017) Bristol: Global City. Working with the world for local and global benefit. February. Bristol: Bristol City Council.

Bulkeley H. (2013) Cities and Climate Change. Abingdon: Routledge.

Campbell T. (2012) Beyond smart cities: How cities network, learn and innovate. London: Earthscan.

Davies J. S. and Imbroscio D. L. (eds) (2010) Critical urban studies: New directions. Albany, NY: State University of New York Press. 
Emerson K. and Nabatchi T. (2015) 'Evaluating the productivity of collaborative governance regimes: A performance matrix', Public Performance and Management Review, 38, 717-747.

Hambleton R. (2007) 'New leadership for democratic urban space' pp. 163176 in Hambleton R. and Gross J. S. (eds) Governing Cities in a Global Era. Urban innovation, competition and democratic reform. Basingstoke: Palgrave

Hambleton R. (2015) Leading the Inclusive City: Place-based Innovation for a Bounded Planet. Bristol: Policy Press.

Hambleton R. (2017) 'The super-centralisation of the English state - Why we need to move beyond the devolution deception'. Local Economy, 32, 1, pp. 313.

Hambleton R. and Sweeting D. (2014) 'Innovation in urban political leadership. Reflections on the introduction of a directly-elected mayor in Bristol, UK', Public Money and Management, 34, 5, pp. 315-322.

Hambleton R. and Sweeting D. (2015) The Impact of Mayoral Governance on Bristol. Bristol: School for Policy Studies, University of Bristol. Available at: www.bristolcivicleadership.net

Hirschman A. O. (1970) Exit, voice and loyalty. Cambridge, MA: Harvard University Press.

Hood C. (1991) 'A public management for all seasons?' Public Administration, 69, Spring, pp. 3-19.

Hoggett P. (1991) 'A new management in the public sector?' Policy and Politics, Vol 19, No 4, pp. 243-256.

John P. and Cole A. (1999) 'Political leadership in the new urban governance: Britain and France compared', Local Government Studies, 25(4), 98-115.

Latham P. (2017) Who stole the Town Hall? The end of local government as we know it. Bristol: Policy Press.

Lowndes V. and Gardner A. (2016) 'Local governance under the Conservatives: super-austerity, devolution and the "smarter state"', Local Government Studies, 42(3), 357-375.

Margerum R. D. (2011) Beyond Consensus. Improving collaborative planning and management. Cambridge MA: The MIT Press.

Mintzberg H. (1996) 'Managing government. Governing management.' Harvard Business Review, May-June, pp. 75-83.

Morris S. (2017) 'Bristol launches "spectrum of activity" to tackle homelessness', The Guardian, 25 January. 
Norton P. and Hughes M. (2017) Public consultation and community involvement in planning. A twenty-first century guide. London: Routledge.

Oliver B. and Pitt B. (2013) Engaging communities and service users: Context, themes and methods. Basingstoke: Palgrave.

Osborne S. P. (ed) (2010) The new public governance? Emerging perspectives on the theory and practice of public governance. Oxford: Routledge.

Pestoff V., Brandsen T. and Verschuere B. (eds) (2012) New public governance, the third sector and co-production. New York, NY: Routledge.

Royal Society of Arts (RSA) (2017) Inclusive Growth Commission. Making our economy work for everyone. March. London: RSA.

Savitch H. V. and Kantor P. (2002) Cities in the international marketplace. Princeton, NJ: Princeton University Press.

Sweeting D. and Hambleton R. (2017) 'Mayoral governance in Bristol: has it made a difference?' pp. 19-34 in Sweeting D. (ed) Directly elected mayors in urban governance. Impact and practice. Bristol: Policy Press.

Torfing, J., Sorensen, E. and Roiseland, A. (2016) 'Transforming the public sector into an arena of co-creation: Barriers, drivers, benefits and ways forward', Administration and Society, 1-31.

Williams P. (2012) Collaboration in Public Policy and Practice. Perspectives on boundary spanners. Bristol: Policy Press.

Yates D. (1977) The ungovernable city. The politics of urban problems and policy making. Cambridge, MA: MIT Press. 
